\title{
Further Relevance Analysis of a General PMO Model
}

\author{
Imre Szalay ${ }^{\mathrm{a}}$, Adam Kovacs ${ }^{\mathrm{b}}$, Zoltan Sebestyen ${ }^{\mathrm{c}, *}$ \\ ${ }^{a}$ CRS Plus Ltd., Fodros köz 5., Budapest, 1039, Hungary \\ ${ }^{b}$ Elfin Ltd., Szent István park 6., Budapest 1137, Hungary \\ ${ }^{c}$ Budapest University of Technology and Economics, Müegyetem rkp. 2. QA307, Budapest 1117, Hungary
}

\begin{abstract}
In our previous publications at this forum, on the one hand, we introduced and described a comprehensive project management offices (PMOs) model, and on the other hand, we conducted a deeper analysis of two elements of our model. With this series of articles, we are trying to underline the lack of the common categories and the conventional interpretation leading to a diverse discussion on PMOs.

Our suggested PMO model contains six elements formed in a Celtic cross shape. In our latest paper we made a deep analysis of the typology and the service categories. The analysis was not only based on a qualitative literature review, but we have also used the publications as an input for a quantitative analysis.

Continuing this approach in this presentation, we will dive deep in the remaining four elements of our model. The viewpoints and inputs for our analysis:

1.Category of Context (the environment of the PMO): industry and business model dependencies, impact of the organizational project knowledge and culture, PMO trends and PMO surveys from different sources

2. Category of Internal processes (of PMO): attempt to define a common set of process group for PMO, features of portfolio management software products

3.Category Performance (the metrics PMO): success factors, KPIs, expectations, balancing among business, project and operational metrics or emphasizing some of them

4.Category Maturity: compering different PMO and project maturity approaches to set up a practical and general proposal.

Beyond making our model complete with all six elements analyzed, the presentation gives a brand-new part with the analysis of the relationships and dependencies among the elements.
\end{abstract}

\section{(C) 2019 The Authors. Published by Diamond Congress Ltd.}

Peer-review under responsibility of the scientific committee of the Creative Construction Conference 2019.

Keywords: Project management office; evaluation framework; maturity; performance; PMO processses; services; typology

\section{Introduction}

As a starting point in our earlier publication [1] along with the quest for the determination of a standardized, integrated, and comprehensive framework, we defined a Project Management Office (PMO) model summarizing grounding ideas of our research. This complex PMO model contains six building blocks that describe the complex role and status of PMO within the organization: the context (the environment of the PMO), the typology, the maturity, the internal

* Corresponding author: Zoltan Sebestyen email: sebestyen@mvt.bme.hu 
Imre Szalay, et al. / Proceedings of the Creative Construction Conference (2019) 048 https://doi.org/10.3311/CCC2019-048

processes of the PMO, the services, and the performance (the metrics of the PMO). This model forms a Celtic cross shape with the main value stream vertically, quality elements horizontally, and important connections among these building blocks called categories. Following the research in our last year publication [2] we focused to show our research method what based on an extensive literature review, and perform the analysis and processing using a mixed, qualitative and quantitative method. In the quantitative part of the research, we analyse the articles as survey elements quantitatively (count them) and build and interpret the model like this. We demonstrated our way of analysis using only two categories from the six ones of the complete model because of size limit of articles here. The result was one hand a unified and complete typology of PMOs according to our qualitative and quantitative deduction and a general service range provided by PMOs. We can summarize our previous result in Table 1 where we show the relations among the found types and defined services groups proving their independency and distinction.

Table 1. Survey elements.

\begin{tabular}{ccccc}
\hline Types/Services & $\begin{array}{c}\text { Operation } \\
\text { support services }\end{array}$ & $\begin{array}{c}\text { Monitoring and } \\
\text { controlling services }\end{array}$ & $\begin{array}{c}\text { Human resource } \\
\text { management services }\end{array}$ & $\begin{array}{c}\text { Strategic and portfolio } \\
\text { management services }\end{array}$ \\
\hline Dedicated PMO & $\mathrm{x}$ & $\mathrm{x}$ & $\mathrm{x}$ & $\mathrm{x}$ \\
Business Unit PMO & $\mathrm{x}$ & $\mathrm{x}$ & $\mathrm{x}$ & $\mathrm{x}$ \\
Enterprise PMO & $\mathrm{x}$ & $\mathrm{x}$ & $\mathrm{x}$ & $\mathrm{x}$ \\
Project Support Office & $\mathrm{x}$ & $\mathrm{x}$ & $\mathrm{x}$ & \\
Center of Project Excellence & $\mathrm{x}$ & &
\end{tabular}

This paper continues the description of our PMO model using the method of article [2] but not going into great detail (again because of the limited space) and defining the categories context, internal/own process, performance, and maturity.

The main purpose of this research series is to provide a developed, integrated new framework for PMOs, which helps to operate and measure PMOs in constantly changing organizations and gives an opportunity to benchmark PMOs to other companies.

\section{Context of PMO}

A PMO is an integral component of its host organization imbued with specific organizational culture, structural dimensions and functional characteristics and it gives a decisive context for PMO setup and operation. A PMO as a strategic unit and an idea integrated with contemporary organization structure gains mandate from strategy and management expectation. Derived from and depending on the contextual relations, a PMO's mission can be for example (quoted from the literature), organizational innovator, knowledge broker, change and renewal agent, and project performance leader. Your PMO should know its capabilities and possibilities and should know well the organization where the PMO is embedded.

Constitutive but rarely emphasized differentia specifics of an organization is whether it is a project-driven or projectdependent entity. Project-Driven Organizations rely on projects directly gaining revenue therefore they are usually more mature from a project culture point of view. Project-Dependent Organizations derive most of their revenues from selling products or services and using projects for the development of new products or processes. We highlighted this - in our opinion - fundamental distinction because we have not found this separation during our intensive analysis, in which we collected the research around PMO's contexts, environment and impacts. We planned to write one original essay on the organizational context of PMO and gather explanative elements to the contextual categories and use only small modifications on these categories. But the research gave such rich content about these categories that we had to modify the original list of contextual factors.

We summarize our results in Table 2, showing the major sources of our analysis but we used shortening composing, renaming and interpretation during our work. 
Imre Szalay, et al. / Proceedings of the Creative Construction Conference (2019) 048

https://doi.org/10.3311/CCC2019-048

Table 1. An example of a table.

\begin{tabular}{|c|c|c|}
\hline $\begin{array}{l}\text { Main contextual } \\
\text { factors }\end{array}$ & Explanative elements & $\begin{array}{l}\text { Source of } \\
\text { elements }\end{array}$ \\
\hline \multirow{3}{*}{$\begin{array}{l}\text { Surrounding } \\
\text { social system } \\
\text { (based on [3]) }\end{array}$} & $\begin{array}{l}\text { Organizational level of working (national or international) } \\
\text { Laws imposed by the government and other regulatory bodies on the organization } \\
\text { financial facilities: stock markets, banks and foreign investors received } \\
\text { The sector that the organization works in } \\
\text { Cultural status in which the organization is involved }\end{array}$ & [4] \\
\hline & Political tension & [3] \\
\hline & $\begin{array}{l}\text { Private or public } \\
\text { Geographic region }\end{array}$ & [5] \\
\hline \multirow{4}{*}{$\begin{array}{l}\text { Economic sector } \\
\text { (based on [6]) }\end{array}$} & Economic tension & [3] \\
\hline & $\begin{array}{l}\text { The sector that the organization works in } \\
\text { The organization's competitive situation }\end{array}$ & [4] \\
\hline & Application areas & [7] \\
\hline & Short term, Long term & [8] \\
\hline \multirow{3}{*}{$\begin{array}{l}\text { The level of } \\
\text { complexity of the } \\
\text { organization } \\
\text { (based on [4]) }\end{array}$} & $\begin{array}{l}\text { Size of the organization } \\
\text { Size of organizational projects } \\
\text { The number and variety of the customers of the organization }\end{array}$ & [4] \\
\hline & $\begin{array}{l}\text { Matrix or non-matrix organizational structure } \\
\text { Size of the organization } \\
\text { Internal or external project customers }\end{array}$ & [6] \\
\hline & Client relationship tension & [3] \\
\hline \multirow{4}{*}{$\begin{array}{c}\text { Project } \\
\text { dimensions }\end{array}$} & $\begin{array}{l}\text { The number and variety of the organization's customers } \\
\text { The role of organization in the project (employer, consultant, contractor) }\end{array}$ & [4] \\
\hline & $\begin{array}{l}\text { Projects with non-direct financial impacts (improved efficiency, user satisfaction and organizational } \\
\text { learning, community benefits, and environment protection) } \\
\text { Competitive potential and/or strategic renewal for future business-investment projects } \\
\text { Public and non-profit projects }\end{array}$ & [19] \\
\hline & Program categories & [7] \\
\hline & Complexity/Uncertainty dimensions & [9] \\
\hline \multirow{3}{*}{$\begin{array}{l}\text { Level of project } \\
\quad \text { culture } \\
\text { (based on }[6])\end{array}$} & $\begin{array}{l}\text { Controlling the project machine tension } \\
\text { Standardisation/flexibility tension }\end{array}$ & [3] \\
\hline & $\begin{array}{l}\text { Relation between organization strategies with PM development } \\
\text { Level of organizational project management maturity } \\
\text { Methods and technologies used in the project } \\
\text { Project management structure in the organization }\end{array}$ & [4] \\
\hline & Level of project management maturity & {$[6]$} \\
\hline \multirow{4}{*}{$\begin{array}{l}\text { The philosophy of } \\
\text { management } \\
\text { (handling events } \\
\text { to be resolved) } \\
\text { (based on [3]) }\end{array}$} & Business versus Process orientation & [3] \\
\hline & $\begin{array}{l}\text { Organizational culture } \\
\text { Delegation of authority in the organization } \\
\text { Project management structure in the organization }\end{array}$ & [4] \\
\hline & Supportiveness of organizational culture & [6] \\
\hline & Management mind set & [8] \\
\hline
\end{tabular}

\section{Own Processes - Internal processes of the PMO}

PMO processes define its operation

- giving a strong framework and regularity for providing services, serving the project-related activities of the organization

- $\quad$ supporting fact-driven measurement of performance of both business and project activities

- ensuring quality and completeness helping the maturity level of both PMO and organizational project culture 
Imre Szalay, et al. / Proceedings of the Creative Construction Conference (2019) 048 https://doi.org/10.3311/CCC2019-048

Therefore, processes are the engine of our model and definitely derived from services groups and in relation to PMO type and process environment defined by organizational context.

The starting point of our process review was service groups (from our previous article on this topic [2]), considering the analysed and listed components of these service groups.

Our intensive literature research led to interesting observations:

- considering the PMO service palette, only the portfolio management service has only deeper process level presentations, others are mentioned only at a high level in the publications on the other categories or aspects of the PMO (strategy, maturity, type, etc.)

- Secondly, we recognized the relevant sources of the details of the processes operating in a PMO are not the academic publications, but the practical guides.

Therefore, in our analysis, the practical sources are presented in a higher number than the Examination Content Outline for Project Management Institute (PMI) Portfolio Management Professional (PfMP $®$ ) certification or the guide of another project management institution (The Office of Government Commerce, United Kingdom (OGC)) standard Management of Portfolios (MoPTM). There was a useful Appendix in Pinto's study [5]about the detailed questions. Again, we got a good and practical input for scanning the PMO process from our earlier work on collecting the PPM and PMO software products and their detailed feature lists and comparisons. Merkhofer [10] gives a good summary of the necessary services, features, processes and we use their tables during our quantitate work.

Beyond these sources, we found ourselves on the academic publications referred to in our article [2] and others mentioned only some examples: [11], [5], [12], [13]. Using similar derivation (composed, renamed, interpretation) to what we demonstrated in our article [2], we can summarize the operating processes at a PMO.

Processes of Strategic and portfolio management services

- - 1- Project component identification, assessment and categorization - 2 - Project component selection and prioritization - 3 - Dependency analysis and portfolio balancing - 4 - Capacity planning and facilitating allocation of organizational resources - 5 - Managing portfolio information flow - 6 - Identifying and managing portfolio changes -7 - Monitoring and maintaining portfolio-level risks - 8 - Creating and managing a portfolio roadmap and scenarios - 9 - Business and portfolio strategy alignment - 10 - Operating project/portfolio governance framework to ensure management control - 11 - Internal and external Stakeholder Engagement /Management - 12 - Value / Benefit Management - 13 - Decision preparation and recommendations

Operations support services

- -1 - Ensuring stability and flexibility, adaptation and innovation in project management standards, methodologies, tools - 2 - Implementing and managing project portfolio information systems - 3 - Managing and collecting actual and historical project files and documentation - 4 - Managing interfaces with project environment - 5 - Providing administrative support based on qualitative and quantitative analyses - 6 Fostering and developing project management awareness and culture within the organization

Monitoring and controlling services

- $\quad 1$ - Monitoring and controlling project delivery by phases and milestones - 2 -Tracking and managing project outcome benefits versus business case - 3 - Supporting for contracting, accounting, handling time sheets - 4 Auditing verification of project acceptance criteria and compliance of project internal processes - 5 - Setting a project measurement system with both hard and soft criteria and dashboards (KPI for resources productivity, project throughput growth) - 6 - Performing a post-completion appraisal on every project - 7 - Supporting issue tracking and estimation of remaining work

Human resources management services

- - 1- Project Track evolution and organize development of project related knowledge - 2 - Select, manage and evaluate project managers - 3 - Provide specialized services for the project manager (consulting, coaching, mentoring, methodology and leadership improvement) - 4 - Assist human resource/staffing assignment and support it with appropriate segmentation - 5 - Use targeted communication to share project knowledge and learning in the organization - 6 - Support project team formation and ensure effective teamwork

\section{Performance of PMOs}

A study by Gartner in 2010 [14] showed that over 7 years every second PMO failed, the main factor of the failure being not providing enough value for the organization they served. In fact, a well performing PMO is a catalyst for greater efficiency in managing a portfolio of projects: it allows the selection of the right project mix, enables more 
Imre Szalay, et al. / Proceedings of the Creative Construction Conference (2019) 048

https://doi.org/10.3311/CCC2019-048

quality work with fewer resources and less risk. But what does well-performing mean exactly and how can we measure performance?

During our literature review, we found that one of the most common ways to measure performance was the setting up of metrics, so called Key Performance Indicators (KPIs). Example of KPIs include ROI (return on investment), staff retention, and resource utilization. It is absolutely key to select the right indicators, follow them, analyse the results, show and communicate the added value of PMO activities to the stakeholders. With this being set, we can have a clear framework on how [15] the PMO can serve the interests of project managers and stakeholders, and at the same time serve as a strategic framework within the company. With KPIs set, we would then consider that PMOs can clearly prove their added value and contribution. However, it is interesting to see that based on some research, a PMO's performance undoubtedly makes a direct contribution to the organization's return on investment (ROI) [16], while Thomas and Mullaly [17] have shown that it is quite impossible to calculate any direct relationship between project management implementation and ROI. Thomas, J. L., \& Mullaly, M. E. bring in the notion of "value" instead of performance in order to capture the business significance of the PMO. Their most significant result is that the notion of fit between the organization and the project management components play the most important role when it comes to obtaining value.

Next to these elements, it is important to consider the link between two other elements of our model: the context of the PMO and PMO type. In comparison with the private sector [18], in the public sector, strategic objectives are not expressed in terms of profit and value to shareholders but with user satisfaction and value for the stakeholders. In the healthcare sector example of Aubry, Richer, Lavoie-Tremblay and Cyr's paper, the problem is very well demonstrated: on the one hand, cost cutting is easily measurable, whereas delivering quality care for the patient factor is much softer. In this case, how can we measure performance?

As far as the performance of the PMO is concerned, rather than providing a common approach for the performance element, we will analyse the connection of the value of the PMO with the PMO context and PMO type.

\section{PMO Maturity}

Initially, when we started our research, we considered maturity as the element of our model that is there to support continuous improvement of an organization: that can be the internal measurement and goal setting support of the PMO:

But what does maturity mean exactly? The Oxford English Dictionary describes 'mature' as "having reached the most advanced stage in a process", so this means that 'maturity' is the condition of being mature [19]. Maturity can also be a bridge that can compare an organization's actual situation with the best practice from other institutions. Besides that, it can also provide new ideas and improvement initiatives coming from the academic world.

The so-called maturity models were developed by the academic field from the beginning of the 2000s and they were a proven approach for IT leaders to improve the effectiveness of their management processes [20]. There are approximately 60 maturity models that we found, most of them based upon the Software Engineering Institute's Capability Maturity Model Integration (CMMI), whereas the processes identified within them are in the Control Objectives for Information and Related Technology (CobiT) framework from the Information Systems Audit and Control Association.

Several organizations such as Gartner, PWC and ESI have developed their own model, where they defined stages to measure the maturity of the PMO. One of the practical maturity models is the maturity cube [5], which includes a wellestablished interview questionnaire and a database of the answers from a large number of companies.

Same as for the other elements of our model, our goal was to propose a summary of maturity levels. However, in the case of maturity, we couldn't propose a synthetized view as we see limited difference between the models. Some research has been done in this area. Woerner has shown that there are two general schools of thought: one is processdriven, and the other is business-driven [21], the first associated with the CMM mentioned above, while the businessdriven models are focusing more on aligning projects with the organization's goals (tactical to strategic). Cooke-Davies 
Imre Szalay, et al. / Proceedings of the Creative Construction Conference (2019) 048 https://doi.org/10.3311/CCC2019-048

[22] has defined 3 types of models: those focusing on the project management process, those focusing on the technical process of developing project outcome and those focusing on organizational maturity. As far as maturity is concerned, we consider that it is more interesting to analyse the impact of the other elements of our model on the increase/decrease of the maturity level. We want to emphasize that the maturity level of a PMO doesn't necessarily imply the development state of the organization, although it is interesting to check the dependency of the maturity movements with our other elements. Susan Hostetter and Sherri Norris [23] also emphasized that the movement amongst the maturity levels is dependent on several external factors as well.

\section{Conclusion and future work}

Based on an exhaustive literature review, we examined the operation of the PMO model we presented, by making our own criteria and using them to analyse and interpret the model. For the sake of completeness, the elements of research so far have to be combined as a whole, and it should be checked against the latest literature. In our research, we examined the connection between the elements of the model and their effect on the content of the constituents. It did not make sense to make a common consolidated list in the case of each model element, but examining the connections was interesting even in these cases (e.g. PMO type/ services, and performance is connected to this).

\section{References}

[1] I. Szalay, Á. Kovács, Z. Sebestyén, Integrated Framework for Project Management Office Evaluation, , in Procedia Engineering, 2017, 196, pp. 578-584. https://doi.org/10.1016/j.proeng.2017.08.033

[2] I. Szalay, A. Kovacs, Z. Sebestyen, Proposal for typology and definitions of service categories in a general PMO model, (2018) pp. 641-648. https://doi.org/10.3311/CCC2018-085

[3] B. Hobbs, M. Aubry, D. Thuillier, The project management office as an organisational innovation, Int. J. Proj. Manag. 26 (2008) pp. 547-555. http://dx.doi.org/10.1016/j.ijproman.2008.05.008

[4] M. Parchami Jalal, S. Matin Koosha, Identifying organizational variables affecting project management office characteristics and analyzing their correlations in the Iranian project-oriented organizations of the construction industry, Int. J. Proj. Manag. 33 (2015) pp. $458-466$. https://doi.org/10.1016/j.ijproman.2014.06.010

[5] A. Pinto, M.F. De Matheus Cota, D.G. Levin, The PMO Maturity Cube, a Project management iffice maturity model, PMI Res. Educ. Congr. 2010, Washingt. D.C., USA (2010) pp. 1-56.

[6] B. Hobbs, M. Aubry, An Empirically Grounded Search for a Typology of Project Management Offices, Proj. Manag. J. 39 (Jan. 2008) pp. S69S82. https://doi.org/10.1002/pmj.20061

[7] A. Stretton, Series on Categorizing Projects and Programs., PM World J. 3 (2014) pp. 1-12.

[8] C. Benko, F.W. McFarlan, Connecting the Dots: Aligning Projects with Objectives in Unpredictable Times. Boston: MA: Harvard Business School Press, 2003.

[9] A. Shenhar, D. Dvir, Reinventing project management : the diamond approach to successful growth and innovation. Harvard Business School Press, 2007.

[10] L. Merkhofer, Free Aid for Evaluating Project Portfolio Management Tools, , $2014 . \quad$ [Online]. Available: http://www.prioritysystem.com/ppmselectionaid.html. [Accessed: 26-Mar-2019].

[11] B. Hobbs, M. Aubry, A Multi-Phase Research Program Investigating Project Management Offices (PMOs): The results of Phase 1, Proj. Manag. J. 38 (2007) pp. 74-86. https://doi.org/10.1177\%2F875697280703800108

[12] Y. Wu, H. Zhang, H. Xu, A Three-Dimensional Project Portfolio Management Framework for Construction Companies, Open Civ. Eng. J. 10 (Jul. 2016) pp. 433-447. http://dx.doi.org/10.2174/1874149501610010433

[13] P. Dietrich, K. Artto, J. Kujala, Strategic Priorities and PMO Functions in Project - Based Firms, , in PMI Research and Education Conference, 2010, pp. 1-31.

[14] PMO Guru, PMO KPI examples can often help you to promote the value and the success of your PMO. You can find PMO KPI examples and metrics here., . [Online]. Available: http://www.pmoguru.com/pmo-kpi-examples-for-measuring-success/. [Accessed: 26-Mar-2019].

[15] T.G.A. Viglioni, J.A.O.G. Cunha, H.P. Moura, A Performance Evaluation Model for Project Management Office Based on a Multicriteria Approach, Procedia Comput. Sci. 100 (2016) pp. 955-962. https://doi.org/10.1016/j.procs.2016.09.257

[16] G.I. Kendall, S.C. Rollins, Advanced Project Portfolio Management and the PMO: Multiplying ROI at Warp Speed, System (2003) p. 434. J. Thomas, M. Mullaly, Researching the Value of Project Management [Available at:
[

[17] http://www.pmi.org/Marketplace/Pages/ProductDetail.aspx?GMProduct=00101065301] Last view 27/10/2010. Project Management Institute, 2008.

[18] M. Aubry, M.C. Richer, M. Lavoie-Tremblay, G. Cyr, Pluralism in PMO performance: The case of a PMO dedicated to a major organizational transformation, Proj. Manag. J. 42 (Dec. 2011) pp. 60-77. https://doi.org/10.1002/pmj.20269

[19] L. Khalema, C. van Waveren, K.-Y. Chan, the Relationship Between Project Management Office Maturity and Organisational Project Management Maturity: an Empirical Study of the South African Government Infrastructure Departments, South African J. Ind. Eng. 26 (2015) pp. 12-26. https://doi.org/10.7166/26-3-1021

[20] Toolkit Best Practices: Program and Portfolio Management Maturity Model, , 2007.

[21] B. Woerner, L. Aziz, Growing up: The information technology project management office (PMO)'s journey from infancy to maturity, , in PMI® Global Congress 2006-North America, 2006.

[22] T.J. Cooke-Davies, A. Arzymanow, The maturity of project management in different industries: An investigation into variations between project management models, Int. J. Proj. Manag. 21 (Aug. 2003) pp. 471-478. https://doi.org/10.1016/S0263-7863(02)00084-4

[23] S. Hostetter, S. Norris, Ranking Portfolio Management Maturity 1,2, , 2017. 